\title{
Investigation and Analysis of Asbestos Fibers and Accompanying Minerals in Biological Materials
}

\author{
by L. Le Bouffant*
}

\begin{abstract}
A method is described for isolating asbestos fibers contained in biological tissues. It consists in incinerating the biological material in activated oxygen at $150^{\circ} \mathrm{C}$, and attacking the ash by $1 \mathrm{~N} \mathrm{HC1}$ for $18 \mathrm{hr}$. The residue is then filtered on a membrane covered with a carbon film. Electron microscope examination of the deposit makes it possible to determine fiber concentrations when the weight or volume of primary material is known, and to make size analyses. By x-ray diffraction, the mineralogical nature of the asbestos is determined by comparison with an aluminum reference diagram. For $x$-ray diffraction, a micromethod is used, with an ash sample of about $10 \mu \mathrm{g}$.

These techniques are used for identifying and counting asbestos fibers in small fragments of lungs or other organs. It was found that asbestos fibers generally go along with other minerals which may be abundant. Most fibers found in lung are less than $5 \mu \mathrm{m}$ long. Counts on lungs of asbestos workers give concentrations often greater than $10^{7}$ particles per gram of dry tissue. The evolution of inhaled chrysotile seems to be different from that of amphiboles. In the case of pleural mesothelioma, a comparison of fibers within the tumor with fibers in the adjacent parenchyma shows only slight differences in the particle sizes, but marked differences in their nature, with a chrysotile enrichment in the pleural zone. Pleural plaques were analyzed in the same way. After decalcification, many small sized asbestos fibers were found. The same technique is now being used for determining ingested particles. A great number of observations concerning fiber counts, their nature and sizes, and the presence of various clays minerals will be necessary to establish the role of the different factors in the formation of lesions caused by the inhalation or the ingestion of asbestos fibers.
\end{abstract}

When one starts on the problem of the identification and quantitative determination of asbestos fibers in biological tissues, it is soon found that the technique of preparation is highly significant for the reliability and even the validity of the analytical results.

Unlike asbestos fibers suspended in air or in homogeneous liquids, which are free in the fluid and thus can be easily collected, particles in histological material are trapped in a tissue which must be destroyed without alteration of the nature and physical characteristics of the particles and also without losing part of them.

\footnotetext{
*Centre d'Etudes et Recherches des Charbonnages de France, B. P. 27,60, Creil, France.
}

After comparing various methods, a technique based on incineration, which was first described in 1969, was adopted. It consists in ashing the biological material in a plasma furnace at low temperature $\left(150^{\circ} \mathrm{C}\right)$ for a period of $2-8 \mathrm{hr}$, depending on the nature and the weight of the sample. Under such conditions, the organic matter is completely destroyed, while asbestos bodies and naked fibers are well preserved.

The influence of the ashing temperature on the characteristics of the chrysotile and amosite fibers was investigated. For that purpose, ground samples of these minerals were submitted to the action of heat under the following conditions: $150^{\circ} \mathrm{C}$ in activated oxygen under reduced pressure $(5 \mathrm{~mm} \mathrm{Hg})$ for $9 \mathrm{hr} ; 450^{\circ} \mathrm{C}$ in 
air for $15 \mathrm{hr}$, then at $600^{\circ} \mathrm{C}$ for $3 \mathrm{hr}$. The latter is the usual condition of sample preparation for quartz content determinations in silicotic lungs. The samples were then examined by electron microscopy and x-ray diffraction. In addition, a systematic study up to $1200^{\circ} \mathrm{C}$ was made.

Chrysotile heated at $150^{\circ} \mathrm{C}$ undergoes no apparent change, either morphological or crystallographical. On the other hand, at $450^{\circ} \mathrm{C}$ the aspect and the crystalline structure of the fibers are markedly modified. If the temperature is still further raised, the structure changes rapidly, and at about $800^{\circ} \mathrm{C}$ chrysotile is transformed into forsterite, $\mathrm{Mg}_{2} \mathrm{SiO}_{4}$.

$\mathrm{Up}$ to $500^{\circ} \mathrm{C}$, amosite, which is more resistant, undergoes no change. On raising the temperature further, there appear progressively the lines of hematite $\mathrm{Fe}_{2} \mathrm{O}_{3}$, which is an indication of the partial decomposition of amosite. At $1000^{\circ} \mathrm{C}$, the lines of amosite have disappeared completely.

Combustion of organic matter is complete after a few hours at $150^{\circ} \mathrm{C}$ in an oxygen plasma, while there remains a carbonaceous residue at $450^{\circ} \mathrm{C}$ after a heating period of $18 \mathrm{hr}$.

From these observations we were led to adopt a technique in which the material is heated at $150^{\circ} \mathrm{C}$ in active oxygen.

\section{Ash Treatment}

Besides asbestos fibers, the ash thus obtained contains various proportions of minerals, such as phosphates, sulfates, carbonates, and iron compounds. This mineral burden makes difficulties for several reasons: during the microscopic examination, it may conceal part of the asbestos fibers, in particular small fibers; during the analysis of the component, it has a dilution effect which in some cases-for example, pleural plaques-may be significant.

It is then desirable to eliminate most of the mineral burden without damaging the asbestos fibers. The method adopted consists in attacking the ash by hydrochloric acid under mild conditions.

To determine the optimum conditions of attack, the action of hydrochloric acid on chrysotile and amosite was studied. The results show that chrysotile attached by $1 N \mathrm{HCl}$ at room temperature undergoes no visible change. On the contrary, rapid destruction is observed under the action of $12 \mathrm{~N} \mathrm{HCl}$ after $30 \mathrm{~min}$.

A more elaborate investigation into the action

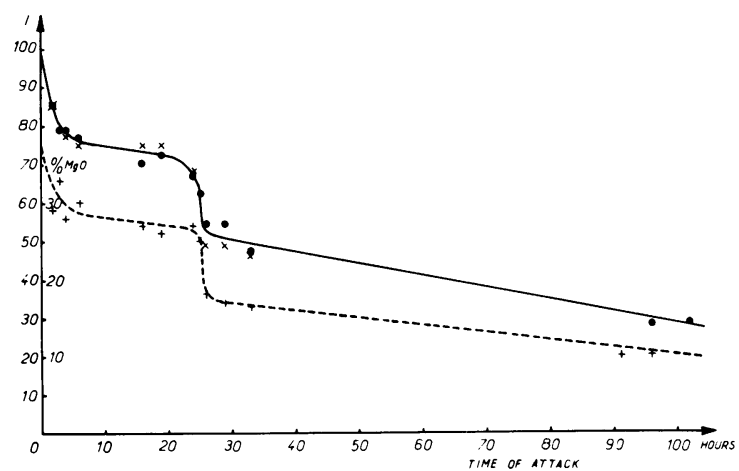

FIGURE 1. Intensity of lines in x-ray diffraction pattern: (O) (002), $7.36 \AA ;(\times)(004), 3.68 \AA ;(-) \mathrm{MgO}$ content $(\%)$ $(+)$

of $1 N$ hydrochloric acid shows that the intensity of the $002(7.36 \AA)$ and $004(3.68 \AA)$ lines of the $\mathrm{x}$ ray diffraction pattern decreases with the time of attack and that there is a correlation between these intensities and the magnesium content (Fig. 1). The curve shows a flat portion between 5 and $20 \mathrm{hr}$. Beyond $22 \mathrm{hr}$ a steep decrease in the line intensity is observed.

Figure 2 shows the combined effect of heating at $150^{\circ} \mathrm{C}$ for $24 \mathrm{hr}$ and treating with $1 \mathrm{~N}$ hydrochloric acid for $1 \mathrm{hr}$. (up to the beginning of

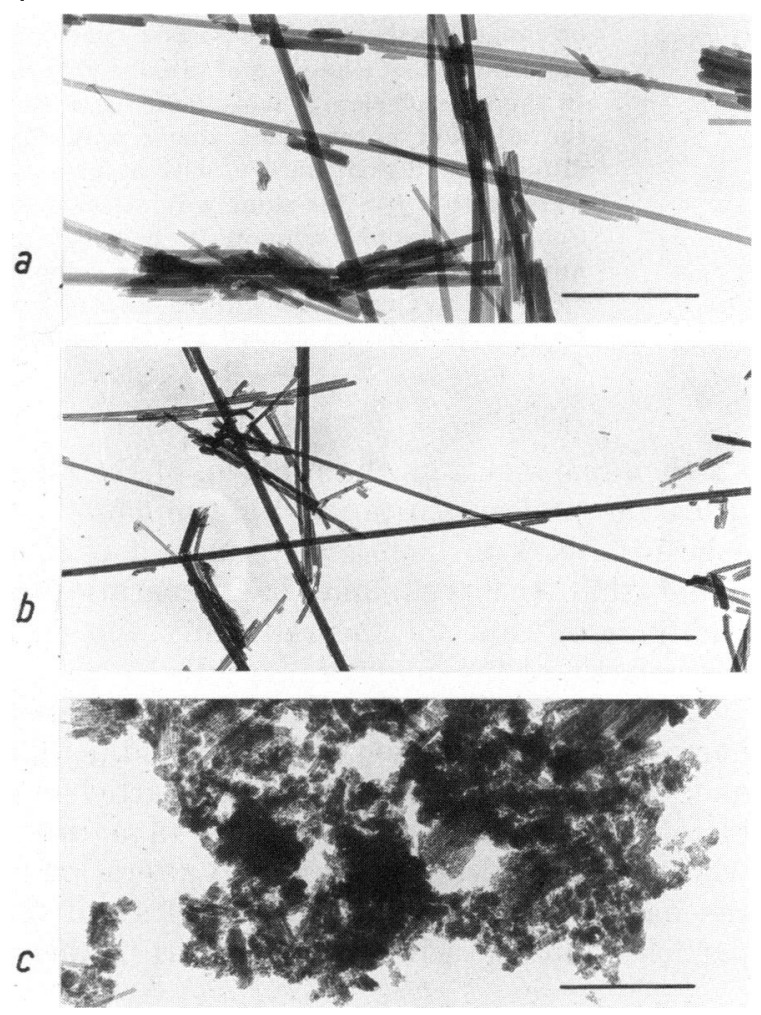

FIGURE 2. Micrographs: (a) untreated chrysotile; (b) chrysotile after heating at $150^{\circ} \mathrm{C}$ and etching with $1 N \mathrm{HCl}$; (c) chrysotile after heating at $450-600^{\circ} \mathrm{C}$ and etching with $1 N \mathrm{HCl}$. 
the flattened portion of the curve, the corresponding weight loss is $16 \%$ ) and of heating at $450-600^{\circ} \mathrm{C}$ followed by acid attack under the same conditions (weight loss $74 \%$ ).

Amosite undergoes no visible change under the action of hydrochloric acid.

Finally, the time of $18 \mathrm{hr}$ was chosen for the attack by hydrochloric acid. The time corresponds to the end of the flat portion of the intensity curve of the diffraction lines.

The effect of this treatment is twofold. As a first result, the microscopic images become more clear. A second effect is an increase in the concentration of asbestos fibers in the prepared sample. The ash content of the material before the hydrochloric attack varies according to the mineral matter content (exogen dust or endogen material): between less than $1 \%$ in parenchyma or pleura, for example, and more than $50 \%$ in pleural plaques, for example. As a result of the attack by acid, the average weight loss in many cases represents about a hundredfold enrichment. Part of the iron of the asbestos bodies is also eliminated by the etching, thus improving considerably the quality of the diffraction diagram, as can be seen in Figure 3.

\section{Further Preparation for Electron Microscopy and Diffraction Analysis}

The residue from the attack by hydrochloric acid is filtered on a membrane covered with a carbon film obtained by vacuum evaporation. Thus the fibers lie flat on the membrane. A second carbon layer is then deposited, and the membrane is cut into two fractions: one for electron microscope examination and electron diffraction, the other for $x$-ray diffraction. This filtration method gives a much more homogeneous deposit than collecting a drop of aqueous suspension, and there is no selection depending on the size distribution.

The fraction intended for electron microscopy is transferred to a grid, and the membrane is eliminated by dissolution. The fraction used for $\mathrm{x}$-ray diffraction has also its membrane dissolved and it is incinerated in a plasma furnace for elimination of the carbon films.

\section{Electron Microscope Examination and Electron Diffraction}

There is nothing particular to say concerning
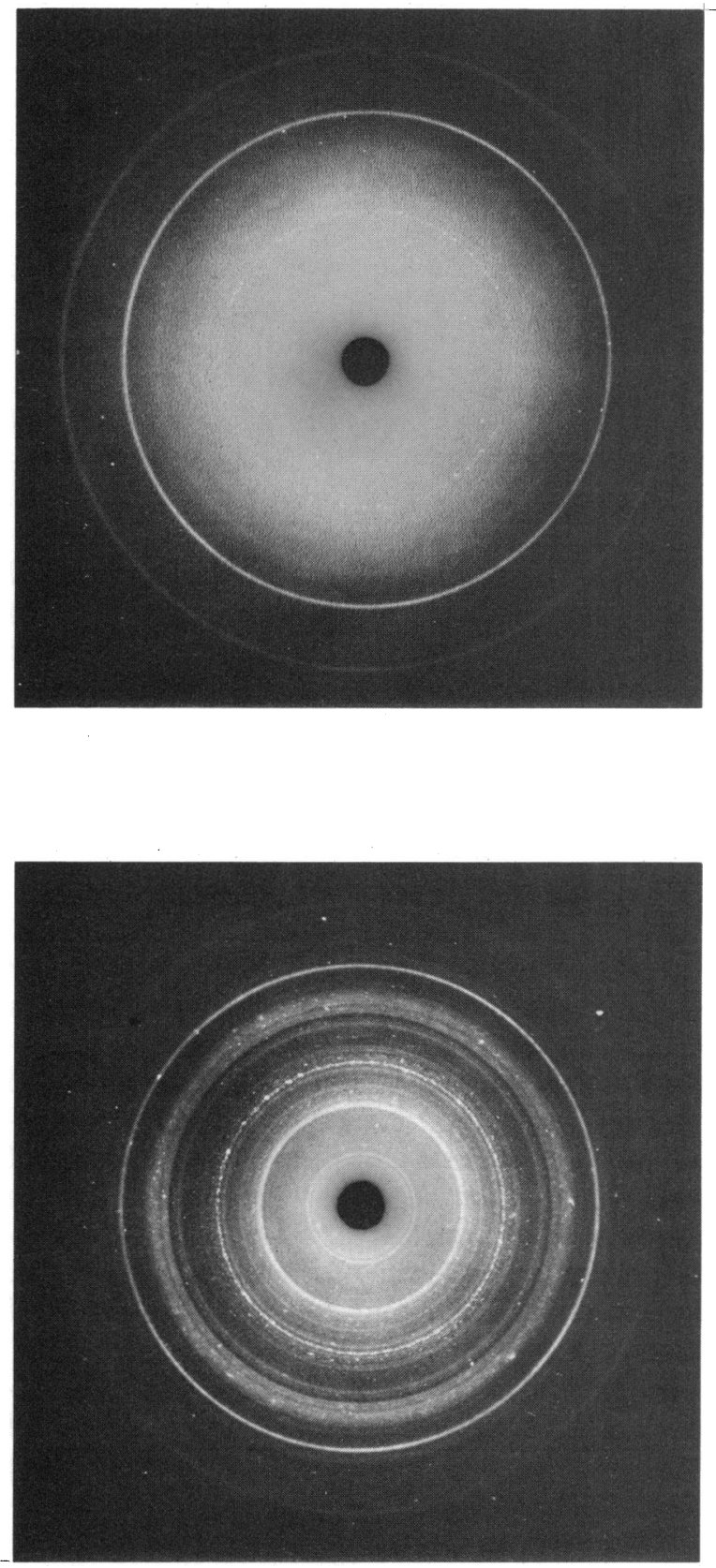

Figure 3. Debye-Scherrer diagrams: (top) ashed at $150^{\circ} \mathrm{C}$; (bottom) ashed at $150^{\circ} \mathrm{C}$, washed with $\mathrm{HCl}$.

the electron microscopic examination. Of course, for the determination of particle numbers, it is necessary to know the quantity of primary material, the surface of the membrane and of the microscope field under examination.

Electron diffraction requires the calibration 
of the diagram for calculating the interplanar spacings. This is performed very simply by deposition of an aluminum film on the preparation, by vacuum evaporation.

\section{X-Ray Diffraction}

In general, the quantity of material required for x-ray diffraction is of a few milligrams. Taking into account the small sizes of some biological samples, this method was adapted to analytical purposes for analysis of a volume of initial tissue of about $1 \mathrm{~mm}^{3}$. The weight of the final sample used after incineration is about 10 $\mu \mathrm{g}$.

The diffraction diagram recorded photographically in a flat chamber is in the form of Debye-Scherrer rings which are more or less punctuated, owing to the very small quantity of matter and to the size of some of the mineral particles. The minerals are identified by measurement of the ring diameter by a standard method.

\section{Applications and Results}

These methods are used systematically for locating and identifying asbestos particles in lungs and other organs. Owing to their sensitivity, it is possible to perform analyses on small samples such as surgical biopsies, expectorations, bronchial biopsies, even in the case of samples with small fiber contents. Since the methods are quantitative, it is possible to determine the concentration of fibers per unit weight or volume of tissue and the size distribution of the particles.

Several facts were thus established by examining the lungs of workers with bronchial carcinoma or pleural mesothelioma and having many years of dust exposure in the asbestos industry.

It was found in particular that asbestos fibers generally go along with other minerals, such as talc, kaolinite, chlorite, or quartz. It often happens that these attendant minerals are in fact present in greater concentrations than in asbestos itself.

Size distribution determinations of intrapulmonary fibers show that most fibers are less than $5 \mu \mathrm{m}$ long (Fig. 4). With respect to this observation, it is recalled that only fibers above

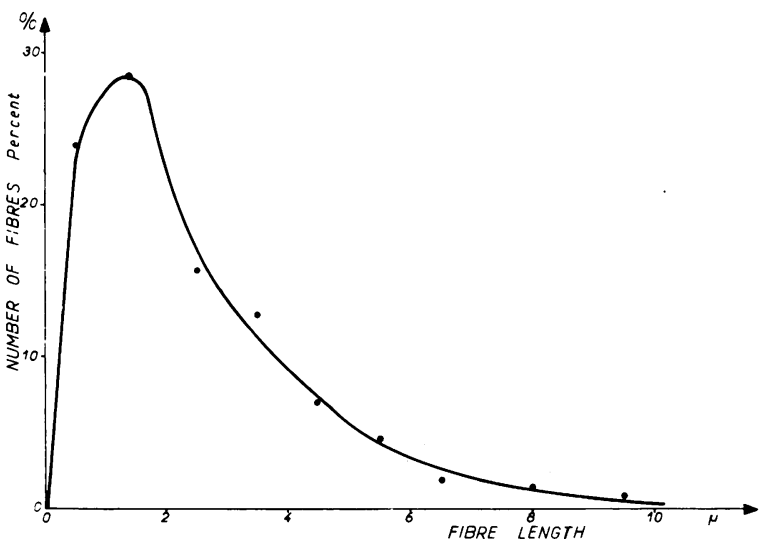

FiguRE 4. Size distribution diagram of intrapulmonary fibers.

$5 \mu \mathrm{m}$ in length are taken into account in atmospheric dust controls.

Fiber counts by electron microscopy on asbestos workers generally give very high intrapulmonary concentrations even within the tumor, frequently from 10 to $50 \times 10^{6}$ particles per gram of dry tissue.

It is noteworthy that chrysotile becomes rare in comparison with amphiboles in the lung parenchyma, even in the case of workers who had been exposed a much longer time to chrysotile than to amphiboles during their professional life.

The reason for the disappearance of chrysotile in the lung is not yet clear. It is thought, however, that this is partly accounted for by the rapid clearance of chrysotile which has a high solubility compared to that of amphiboles. To confirm this, a comparative study of lung clearance with different mineral dusts was carried out on rats. The animals inhaled dust for $6 \mathrm{hr}$ in concentrations of $300 \mathrm{mg} / \mathrm{m}^{3}$, and groups of animals were killed at different times. The dust retained in the lung was determined by colorimetry ( $\mathrm{Si}$ determination in the case of chrysotile). Figure 5 (parts of the curves with the gentlest slope) shows that the rate of alveolar clearance of chrysotile is significantly different from that of other insoluble or slightly soluble minerals.

Pleural mesotheliomas in asbestos workers were examined in the same way. From a limited series of examinations it appears that the size 


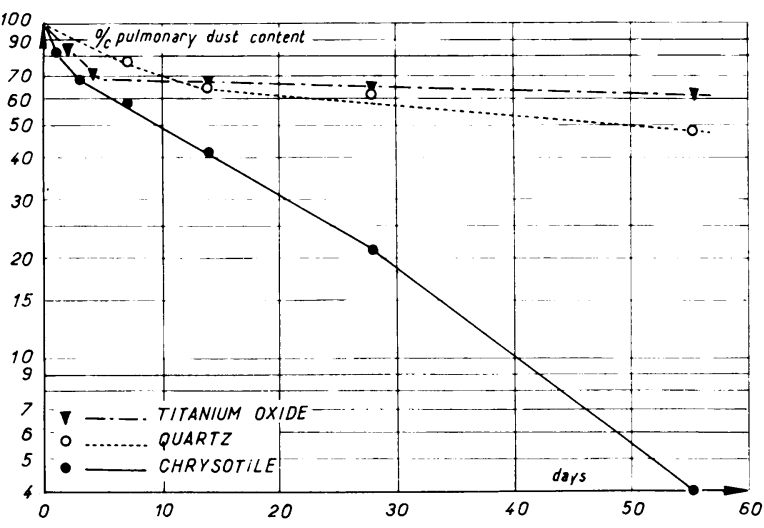

Figure 5. Plot of pulmonary dust content: (\) titanium oxide; (o) quartz; $(\bullet)$ chrysotile.

distribution of the fibers within the tumor is not very different from that found in the parenchyma (Fig. 6). On the other hand, the distribution of the fibers seems to be markedly changed. As a matter of fact, in several cases of mixed dusts (chrysotile-amphiboles), there is a significant chrysotile enrichment in the pleural tumor, contrary to the observations in the lung parenchyma in which as reported above, a relative amphiboles enrichment was found. It thus appears that the chrysotile impoverishment of the parenchyma cannot be accounted for only by the dissolution of this mineral, but that there seems to be a preferential drainage of chrysotile towards the pleura.

Table 1 gives the number of fibers found within the tumor and in the adjacent lung tissue in three cases of pleural mesothelioma.

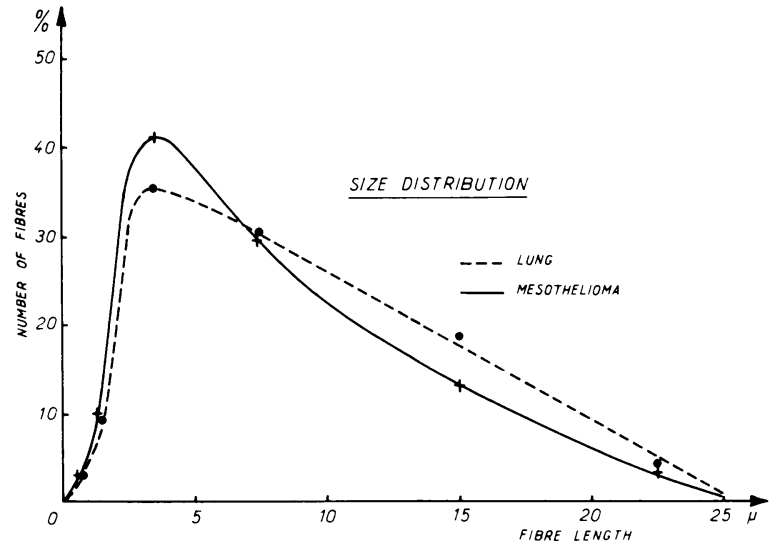

FiguRE6. Size distribution: (--) lung; (-) mesothelioma.
Table 1. Number of fibers $N$.

\begin{tabular}{|c|c|c|c|}
\hline \multirow[b]{2}{*}{ Case } & \multicolumn{2}{|c|}{ Number of fibers $N / g$ tissue } & \multirow{2}{*}{$\frac{N \text { in tumor }}{N \text { in lung }}$} \\
\hline & Lung & Tumor & \\
\hline 1 & $17.4 \times 10^{6}$ & $18.6 \times 10^{6}$ & 1.07 \\
\hline 2 & $1600 \times 10^{6}$ & $13 \times 10^{6}$ & 0.008 \\
\hline 3 & $34 \times 10^{6}$ & $1.2 \times 10^{6}$ & 0.035 \\
\hline
\end{tabular}

Many fibers are found in each case in the tumor region. In one case there are as many fibers in the tumor as in the lung.

Finally, fibrohyaline and calcified pleural plaques were analyzed in the same way. After concentrating as described above, many small fibers were found in several cases (Table 2).

Table 2

\begin{tabular}{lcc}
\hline & \multicolumn{2}{c}{ Number of fibers $N /$ g dry tissue } \\
\cline { 2 - 3 } & Case 1 & Case 2 \\
\hline Fibrohyaline tissue & $6 \times 10^{6}$ & $3.6 \times 10^{6}$ \\
$\begin{array}{l}\text { Calcified tissue (length } \\
\text { of fibers 0.1-2 } \mu \mathrm{m})\end{array}$ & $30 \times 10^{6}$ & $40 \times 10^{6}$ \\
\begin{tabular}{l} 
Corresponding lung \\
\hline
\end{tabular} & $10 \times 10^{6}$ & $1.6 \times 10^{6}$ \\
\hline
\end{tabular}

By comparing the central calcified zone with the external fibrohyaline zone of a pleural plaque, it is found that the fiber concentration is greater in the calcified zone than in the fibrohyaline zone.

\section{Conclusion}

These few findings illustrate the possibilities of the method described for the qualitative and quantitative determinations of asbestos fibers in lung tissues. Although the results stated refer to lung analyses, the method is, of course, applicable to the determination of asbestos fibers in any other organ or tissue, without exception, and in particular to the study of ingested particles. It appears necessary now to total up count results and analytical data to establish the statistical significance of the different factors, in particular concerning the number, mineral composition, fiber size, and the role of the attendant minerals in the formation of lesions caused by the inhalation or ingestion of asbestos fibers. 